\title{
Awareness about Cyberbullying on Social Media among Female Students in a Malaysian Public University
}

\author{
Nor Hazlyna, $\mathbf{H}^{1}$, Alawiyah Abd Wahab ${ }^{2}$, Fauziah Miswari ${ }^{3}$, Nurainaazuwa Zulkipli ${ }^{4}$, Nur Izzati Ghazali $^{5}$, \\ Siti Marsitah Abdul Razak ${ }^{6}$
}

${ }^{1,2}$ School of Computing, Universiti Utara Malaysia (UUM), Sintok Kedah Darul Aman, Malaysia

${ }^{3,4,5}$ School of Multimedia Technology and Communication,

Universiti Utara Malaysia (UUM), Sintok Kedah, Malaysia

hazlyna@uum.edu.my ${ }^{1}$

Article History: Received: 10 November 2020; Revised: 12 January 2021; Accepted: 27 January 2021;

Published online: 05 April 2021

\begin{abstract}
This study is conducted to analyse the reasons for cyberbullying and the effects of cyberbullying on social media among female students at a university in Northern Peninsular Malaysia. One hundred female students participated in this study through online survey. Majority of the respondents are well-versed pertaining to cyberbullying and are not involved in cyberbullying. The results indicate that female students are exposed to cyberbullying on social media, namely Instagram, Facebook and Twitter and others. This is because the female students use social media daily and are more insecure and sensitive on the words hurled in social media.
\end{abstract}

Keywords: Cyberbullying, Social Media, Female, Students

\section{Introduction}

The advancement of information and communication technologies including in the increase of Internet access have benefitted both the youth and adults. They are able to access to information within a click from smartphones, tablet or laptop. There are many advantages as well as disadvantages on the use of Internet. Information of current issues are obtained within minutes and updated frequently compared to obtained information the next day from print-newspapers. Moreover, users are able to follow issues that are trending on real-time; however, they must exercise discretion on the types of information to be accepted and rejected, respectively. Rumours spread faster with the advent of internet and readers are quick to give negative comments online without reading thoroughly the news or only by hearsay. Thus, this can cause physical and mental health problems to the users as well as the victim.

Cyberbullying is defined as repeated acts of aggressive behaviour over time through the use of electronic devices such as social networking sites and email (Quintana-Orts et al., 2018). The internet and social media nowadays are viewed as avenues to hurl negative comments without taking accountability. Cyberbullying is related to negative outcomes. The study by Abaido (2019) revealed that cyberbullying and online harassment are problems for users of social media, especially young people. Cyberbullying is the act of harassing people on social media or any other online medium by sending or posting messages that are untoward messages, usually anonymously or intentionally by a person or in a group using digital devices such as smartphones, tablets and computers (Abaido, 2019).

Cyberbullying could occur through text messages as well, but mostly users are more active online on social media from their own account or fake accounts created on Facebook, Instagram, Snapchat, and Twitter to harass or embarrass other people.

College students are an important population to focus on the issue of cyberbullying because this period is a unique time for identity formation choices that can be stressful for them. Therefore, the purpose of this research is to study the impact of cyberbullying on social media among female students at a university in Peninsular Malaysia. Specifically, the objectives of the research are (a) To identify the reasons students are involved in cyberbullying, (b) To investigate the effects of cyberbullying, and (c) To recommend awareness programs.

\section{Literature Review}

Cyberbullying is a new form of bullying through internet technology that can be subcategorized into text messages, bullying, pictures, videos clips and phone calls (Asanan et al., 2017). The main actions of cyberbullying include threats, name-calling, social isolation, spreading rumours, and sharing private information (Johnsonet al., 2016). In a study conducted by Rosli (2018), it was reported that Malaysia is placed at sixth place in a survey 
measuring cyberbullying among 28 countries. The study was conducted by using comparative technology, and the survey found that $23 \%$ of Malaysian parents surveyed believed that their child has become a victim of the cyberbully. Out of the 28 countries surveyed, Malaysia ranks as the second country in Asia to have the highest cyberbullying rate, in comparison to India (37\%), Saudi Arabia (19\%), China (17\%), South Korea (13\%) and Japan.

The negative emotions that victims produce, such as feelings of anger, sad and lost could reduce the ability to solve this social problem effectively and lead the victims to have a bad experience in their whole life; thus, cyber bullying victims tend to engage in bullying behaviours. The implications include anger, humiliation, depression, being insecure, lack of self-esteem, embarrassment, suicidal, frustration, having family issues, academic challenges, prone to self-harm, and many more (Odora, 2015). Meanwhile, in the context of gender, females are more sensitive pertaining to appearance or personal opinions. Based on the respondents' demographic background, the research conducted by Balakrishnan (2015) on 393 youths between the ages of 17 to 30 shows that females out-numbered males as bullies and victims, and younger respondents engage in cyber bullying more than older respondents.

Lenhart (2015) argues that girls have a higher preference for visual social media such as Instagram and text messaging apps. Cyberbullying is a growing problem and has been linked to media use and has become a public health concern that can lead to mental and behavioral health problems and an increased risk of suicide (Garett et al.,2016). Johnson et al.(2016) in their study mentioned thatamong the reasons of cyberbullying is the increase use of technology and social media among college students. This is an issue that needs to be addressed immediately, and authorities including parents and colleges as well as universities should focus on this issue so that cyberbullying can be prevented. Cyberbullying behaviours are becoming more visible in high school and college-aged populations (Patchin \& Hinduja, 2015). Cyberbullying can occur at different age levels, with any gender but majority of females can relate to physical, cultural, racial, and even religious biases.

Cyberbullying against female students is alarming and disturbing globally and the cyberbullying problem has gained only limited academic publication attention (Chukwuere et al., 2017). Cyberbullying among students is a topic that has been carefully researched. In the context of gender, research shows that men and women exhibit different patterns of behaviour in relation to bullying. However, most of the previous studies (Chukwuere et al., 2017) focused more on cyberbullying and bullying in general, only few mentioned girl child or female students. This research will investigate the effect of cyberbullying on social media among female students to fill the gaps.

\section{Cyberbullying on social media}

Cyberbullying always happens on social media sites. This is because social media like Facebook, Instagram, Twitter, and other platform are easy to access for everyone including young and old people. Social freedoms often take place on social media including online games. In the study conducted by Cook(2020), it was noted that $19.2 \%$ of cyberbullying occurred through websites and social media applications. From a previous survey about social media (Grigonis, 2017), more youths experienced cyberbullying on social media like Instagram than at other platforms at $42 \%$ with Facebook at 37 percent. Snapchat ranked third at $31 \%$ followed by YouTube at $10 \%$, and other social media platforms record minimum cyberbullying. Majority of teens have experienced some form of cyberbullying. In a similar research by Kshetri and Voas (2019) it was found that 59\% of teens in the United States of America are bullied or being bullied online, and is perceived as a major problem among teenagers.

Cyberbullying on social media influences beyond self-harm. The implications include depression, embarrassment, anger, humiliation, lack of self-esteem and confidence, loneliness, suicidal ideas, insecurity, harassment, and family issues (Odora, 2015). Cyberbullying is deemed to create negative online reputations for victims, which is able to impact college admissions, employment, and other areas of life, and may even cause more serious and permanent consequences of self-harm and suicide (Lu et al., 2020). Cyberbullying victims may experience depression or worse may commit suicide. Therefore, the evidence specific to cyberbullying focuses totally on associations with emotional problems and suicidal attempts.

Previous studies have examined the prevalence and frequency of cyberbullying among college students, with a focus on social media, and perceptions of cyberbullying as a function of features of the targets (Whittaker et al., 2014). In addition, social media sites provide an environment where victims are often the targets of cyberbullies that occur at common social networking sites (Johnson et al., 2016). This is due to the excessive use of social media among teenagers and college students. Therefore, it is important for parents to monitor their children to reduce addictive use of technology from being cyberbullied. 


\section{Cyberbullying among Students}

University students have a higher chance to be exposed to the world of cyber as they use computer and internet technology for a longer time due to the needs of their studies.

Several studies have also identified disadvantages of cyberbullying. Research on Malaysian students in higher learning institutions found that the most common effect of cyberbullying is the development of over-sensitive behaviour towards their surroundings (Lai et al., 2017).

Moreover, a similar research by Muhammad Shawal et al. (2017), adopted a survey research designed by using questionnaire, and 397 undergraduate students from International Islamic University Malaysia (IIUM) took part in the data collection. In that research, the respondents' demographics including gender and results indicated that female students represented most of the studies. Attitude has been defined as a person's negative feeling towards an object that may contribute to misbehaviour such as lying. Various harassments on social networking sites such as stalking are considered as misbehaviour. The result of this study is important because with that such attitude may predict a person's actual behavior. This is one of the ways to know the tendency of people to commit cyberbullying and the impacts of their action.

In the fight against cyberbullying, students need to learn the responsibilities associated with using technology. The students need to be aware on the misuse of technology so that responsible behavior can be improved at an early age. Furthermore, the students must also understand the dangers of cyberbullying.

\section{Method}

This study was designed primarily to create awareness about cyberbullying on social media among female students. The questionnaire was designed to explore students' experiences and understanding of cyberbullying. The questionnaire was developed based on previous studies on cyberbullying and the theory of planned behavior. The target population of this study was female students in a university. This section explains the research procedures of this study including participants, data collection procedures, and data analysis.

\section{Literature review}

The literature reviews were conducted by examining the existing research related to cyberbullying on social media including references from journals, books, proceedings, and newspapers. Articles considered for this review were published from year 2015 to 2020 .

\section{Survey}

The survey questionnaire designed using the google form were distributed through social media applications such as WhatsApp group and Facebook. The questions in the questionnaire explained about the factors, effects and steps taken about cyberbullying. The questionnaire was divided into several sections namely 1) Demographics data (age, semester, and nationality of respondents), 2) Level of knowledge about cyberbullying, 3) Attitudes on cyberbullying, 4) Subjective norms or social pressure to perform cyberbullying, 5) Types ofsocial media platform used, 6) Viewpoints about social media addict and what form of cyberbullying on social media, and 7) Perceived behavioral control or feelings to perform cyberbullying

\section{Participants}

This research was conducted at a university in the Northern Peninsular Malaysia. The target respondents were female undergraduate students.

\section{Results}

Table 1 shows the age distribution of the respondents. The results of the study indicate that, from 100 respondents, $1 \%(\mathrm{~N}=1)$ of the respondents are 19 years old, 3\% $(\mathrm{N}=3)$ are 20 and 24 years old, respectively, $41 \%$ $(\mathrm{N}=41)$ are 21 years old, $43 \%(\mathrm{~N}=43)$ are 22 years old and the other $9 \%(\mathrm{~N}=9)$ are 23 years old.

Table 1. The age of the respondents

\begin{tabular}{|l|c|c|}
\hline Age & $\mathbf{N}$ & \% \\
\hline 19 & 1 & 1 \\
\hline 20 & 3 & 3 \\
\hline 21 & 41 & 41 \\
\hline 22 & 43 & 43 \\
\hline
\end{tabular}


Nor Hazlyna, H., Alawiyah Abd Wahab, Fauziah Miswari, Nurainaazuwa Zulkipli, Nur Izzati Ghazali, Siti Marsitah Abdul Razak

\begin{tabular}{|l|c|c|}
\hline 23 & 9 & 9 \\
\hline 24 & 3 & 3 \\
\hline TOTAL & $\mathbf{1 0 0}$ & $\mathbf{1 0 0}$ \\
\hline
\end{tabular}

Table 2 shows the nationality status of the respondent. All the respondents are Malaysian at $100 \%(\mathrm{~N}=100)$.

Table 2. The nationality status of the respondents

\begin{tabular}{|l|c|c|}
\hline Nationality & $\mathbf{N}$ & \% \\
\hline Malaysian & 100 & 100 \\
\hline Non-Malaysian & 0 & 0 \\
\hline TOTAL & $\mathbf{1 0 0}$ & $\mathbf{1 0 0}$ \\
\hline
\end{tabular}

Table 3 shows the semester of the respondents. From the survey, 2\% (N=2) are in semester 1, 8\% (N=8) are in semester 2, and $2 \%(\mathrm{~N}=2)$ of the respondents are in semester 3. Meanwhile, $73 \%(\mathrm{~N}=73)$ of the respondents are in semester 4 , followed by $1 \%(\mathrm{~N}=1)$ in semester 5 , and $12 \%(\mathrm{~N}=12)$ of the respondents in semester 6 . Finally, $1 \%(\mathrm{~N}=1)$ of the respondents are respectively in semester 7 and 8 .

Table 3. The semester of the respondents

\begin{tabular}{|l|c|c|}
\hline Semester & N & \% \\
\hline 1 & 2 & 2 \\
\hline 2 & 8 & 8 \\
\hline 3 & 2 & 2 \\
\hline 4 & 73 & 73 \\
\hline 5 & 1 & 1 \\
\hline 6 & 12 & 12 \\
\hline 7 & 1 & 1 \\
\hline 8 & 1 & 1 \\
\hline TOTAL & $\mathbf{1 0 0}$ & $\mathbf{1 0 0}$ \\
\hline
\end{tabular}

Table 4 shows the respondent's level of knowledge about cyberbullying, experience of being a cyberbullying victim and being a cyberbullying perpetrator. Respondent's level of knowledge about cyberbullying shows that most of the respondents at $97 \%(\mathrm{~N}=97)$ know about cyberbully and the 3\% $(\mathrm{N}=3)$ refers to respondents that do not know about cyberbully. Next, respondent's experience of being a cyberbullying victim shows that the university students were once being a cyberbullying victim at $12 \%(\mathrm{~N}=12)$, which is lower than students that have never been a cyberbullying victim, which is $88 \%(\mathrm{~N}=88)$. Meanwhile, respondent's experience of being a cyberbullying perpetrator shows that the university students have never cyberbullied anyone at $86 \%(\mathrm{~N}=86)$, which is higher than university students that had cyberbullied someone, $14 \%(\mathrm{~N}=14)$.

Table 4. Respondent's level of knowledge about cyberbullying, respondent's experience of being a cyberbullying victim and being a cyberbullying perpetrator

\begin{tabular}{|l|c|c|}
\hline $\begin{array}{l}\text { Do you know what cyberbully } \\
\text { is? }\end{array}$ & N & \% \\
\hline Yes & 97 & 97 \\
\hline No & 3 & 3 \\
\hline $\begin{array}{l}\text { Are you a victim of cyberbul- } \\
\text { ly? }\end{array}$ & & \\
\hline Yes & 12 & 12 \\
\hline No & 88 & 88 \\
\hline $\begin{array}{l}\text { Have you ever cyberbullied } \\
\text { someone? }\end{array}$ & & \\
\hline Yes & 14 & 14 \\
\hline No & 86 & 86 \\
\hline TOTAL & $\mathbf{1 0 0}$ & $\mathbf{1 0 0}$ \\
\hline
\end{tabular}

Table 5 shows there is a difference between university students in terms of whether they are addicted to social media at $68 \%(\mathrm{~N}=68)$, which is higher than the university students that are not addicted to social media, $32 \%$ $(\mathrm{N}=32)$. 
Table 5. Respondents' viewpoints about social media addict

\begin{tabular}{|l|c|c|}
\hline $\begin{array}{l}\text { Do you consider yourself } \\
\text { addicted to social me- } \\
\text { dia? }\end{array}$ & $\mathbf{N}$ & \% \\
\hline Yes & 68 & 68 \\
\hline No & 32 & 32 \\
\hline TOTAL & $\mathbf{1 0 0}$ & $\mathbf{1 0 0}$ \\
\hline
\end{tabular}

Table 6 shows respondents' viewpoint about the factors why cyberbullying happened on social media. Majority of respondents choose emotions at $43 \%(\mathrm{~N}=43)$ that includes experiencing anger, hatred, annoyed, sad or happy when they thought about cyberbullying, 24\% ( $\mathrm{N}=24)$ of the respondents select low confidence level, $17 \%$ $(\mathrm{N}=17)$ choose bad past experience, and the lowest percentage is $9 \%(\mathrm{~N}=9)$ and $7 \%(\mathrm{~N}=7)$ that choose stress and revenge as a factor of cyberbullying on social media, respectively.

Table 6. Respondents' viewpoints about factors of cyberbullying on social media

\begin{tabular}{|l|c|c|}
\hline $\begin{array}{l}\text { Why do you think cyberbullying } \\
\text { happens on social media? }\end{array}$ & $\mathbf{N}$ & \% \\
\hline Low confidence level & 24 & 24 \\
\hline Emotions & 43 & 43 \\
\hline Bad experience & 17 & 17 \\
\hline Stress & 9 & 9 \\
\hline Revenge & 7 & 7 \\
\hline TOTAL & $\mathbf{1 0 0}$ & $\mathbf{1 0 0}$ \\
\hline
\end{tabular}

Table 7 shows the survey examined about which social media application that respondents experience or view cyberbullying. Majority of the respondents choose Facebook at 37\% (N=37), 29\% (N=29) choose Instagram, 26\% ( $=26)$ choose Twitter; 3\% (N=3) choose WhatsApp and YouTube, respectively and the lowest is ask.fm or curiouscat at $2 \%(\mathrm{~N}=2)$.

Table 7. Respondents' viewpoint about which social media application they often see cyberbullying

\begin{tabular}{|l|c|c|}
\hline $\begin{array}{l}\text { Which social media application that you } \\
\text { often see cyberbullying happen? }\end{array}$ & $\mathbf{N}$ & \% \\
\hline Instagram & 29 & 29 \\
\hline Facebook & 37 & 37 \\
\hline Twitter & 26 & 26 \\
\hline Ask.fm or curiouscat & 2 & 2 \\
\hline WhatsApp & 3 & 3 \\
\hline YouTube & 3 & 3 \\
\hline TOTAL & $\mathbf{1 0 0}$ & $\mathbf{1 0 0}$ \\
\hline
\end{tabular}

Table 8 shows the respondents' viewpoint about form of cyberbullying on social media. The findings indicate that $58 \%(\mathrm{~N}=58)$ of the respondents reported that the most common form of cyberbullying is mean comments, followed by spreading rumours at $21 \%(\mathrm{~N}=21), 13 \%(\mathrm{~N}=13)$ stated post hurtful pictures or videos, meanwhile, $6 \%(\mathrm{~N}=6)$ choose threat to hurt; and the $2 \%(\mathrm{~N}=2)$ of the respondents choose hacking into account as a form of cyberbullying.

Table 8. Respondents' viewpoint about form of cyberbullying on social media

\begin{tabular}{|l|c|c|}
\hline What form did the cyberbullying on social media? & $\mathbf{N}$ & $\mathbf{\%}$ \\
\hline Spread rumours & 21 & 21 \\
\hline Mean comments & 58 & 58 \\
\hline Threat to hurt & 6 & 6 \\
\hline Hacking into account & 2 & 2 \\
\hline Post hurtful pictures or videos & 13 & 13 \\
\hline TOTAL & $\mathbf{1 0 0}$ & $\mathbf{1 0 0}$ \\
\hline
\end{tabular}

Table 9 shows the viewpoint of the university students on their feelings when they were being cyberbullied. The survey indicated that $45 \%$ of the respondents reported that they felt depressed, followed by $28 \%(\mathrm{~N}=28)$ of 
Nor Hazlyna, H., Alawiyah Abd Wahab, Fauziah Miswari, Nurainaazuwa Zulkipli, Nur Izzati Ghazali, Siti Marsitah Abdul Razak

the respondents reported that they felt sad, 19\% ( $\mathrm{N}=19)$ felt embarrassed, and $8 \%(\mathrm{~N}=8)$ stated that they felt scared when they are being cyberbullied.

Table 9. Respondents' viewpoint about their feeling when they were being cyberbullied

\begin{tabular}{|l|c|c|}
\hline $\begin{array}{l}\text { How did you feel when you were } \\
\text { being cyberbullied? }\end{array}$ & $\mathbf{N}$ & \% \\
\hline Happy & 0 & 0 \\
\hline Embarrassed & 19 & 19 \\
\hline Scared & 8 & 8 \\
\hline Depressed & 45 & 45 \\
\hline Sad & 28 & 28 \\
\hline TOTAL & $\mathbf{1 0 0}$ & $\mathbf{1 0 0}$ \\
\hline
\end{tabular}

Table 10 shows the frequency of respondents' feelings if they cyberbully someone. From the survey, $42 \%$ $(\mathrm{N}=42)$ of the respondents reported that they feel sad when cyberbullying someone, 38\% ( $\mathrm{N}=38)$ reported that they feel satisfied, $17 \%(\mathrm{~N}=17)$ reported that they feel powerful, $2 \%(\mathrm{~N}=2)$ reported that they feel happy, and $1 \%$ $(\mathrm{N}=1)$ reported that they feel proud when cyberbullying someone.

Table 10. Respondents' feelings if they cyberbullying someone

\begin{tabular}{|l|c|c|}
\hline $\begin{array}{l}\text { How would you feel if you } \\
\text { cyberbully someone? }\end{array}$ & N & \% \\
\hline Happy & 2 & 2 \\
\hline Powerful & 17 & 17 \\
\hline Satisfied & 38 & 38 \\
\hline Proud & 1 & 1 \\
\hline Sad & 42 & 42 \\
\hline TOTAL & $\mathbf{1 0 0}$ & $\mathbf{1 0 0}$ \\
\hline
\end{tabular}

Lastly, Table 11 shows the best way to stop cyberbullying on social media. The findings of the survey indicate that about $46 \%(\mathrm{~N}=46)$ of the respondents choose to enforce cyberbullying laws, $26 \%(\mathrm{~N}=26)$ of the respondents mention that service providers should take more responsibility for online material. Meanwhile, $12 \%$ $(\mathrm{N}=12)$ of the respondents choose campaign and conferences on cyberbullying as a way to stop cyberbullying on social media, and lastly, community drop in centres and punish the cyberbully shared the same result which are $8 \%(\mathrm{~N}=8)$.

Table 11. The best way to stop cyberbullying on social media

\begin{tabular}{|l|c|c|}
\hline $\begin{array}{l}\text { What do you think is the best way } \\
\text { to stop cyberbullying on social } \\
\text { media? }\end{array}$ & $\mathbf{N}$ & \% \\
\hline $\begin{array}{l}\text { Have community drop in centres } \\
\text { where they can go and get help }\end{array}$ & 8 & 8 \\
\hline $\begin{array}{l}\text { Service providers take more respon- } \\
\text { sibility for online material }\end{array}$ & 26 & 46 \\
\hline Enforce cyberbullying laws & 46 & 12 \\
\hline $\begin{array}{l}\text { Campaign and conferences to talk } \\
\text { about cyberbullying }\end{array}$ & 12 & 8 \\
\hline Punish the cyberbully & 8 & $\mathbf{1 0 0}$ \\
\hline TOTAL & $\mathbf{1 0 0}$ & \\
\hline
\end{tabular}

\section{Discussion}

In this study, the highest number of respondents were 22 years old at $43 \%(\mathrm{~N}=43)$ in Table 1. Compared to similar research by Muhammad Shawal et al. (2017), the highest age recorded in the study was 21 years old with 127 respondents at $32 \%$ with the mean 21.59 and standard deviation 1.328 . Nonetheless, based on this study, the highest percentage of that age does not affect the awareness of cyberbullying because the average age of students in UUM are 22 years old. 
In this research, this study indicate that the highest number of respondents are from semester 4 with the percentage of $73 \%$ and the number of respondents were 73 as in Table 3. The respondents in this study are from semester 1 to semester 8 students. Compare to other research (Muhammad Shawal et al., 2017), as for the respondents' level of study, majority of the respondents are first year students with the percentage of $39.8 \%$ $(\mathrm{N}=158)$, followed by second year with the percentage of $34 \%(\mathrm{~N}=135)$, third year with the percentage $21.2 \%$ $(\mathrm{N}=84)$, and only $5 \%(\mathrm{~N}=20)$ of fourth year students.

Furthermore, majority of the respondents know about cyberbullying. This is obvious when 97\% (N=97) of the respondents choose 'Yes' on the questionnaire. In the baseline paper (Şentürk \& Bayat, 2016), the sensitivity of the students related to Cyberbullying Scale is seen to be low. In other words, this research concludes that most of the respondents are aware about cyberbullying. Thus, when the students are aware about cyberbullying, they can prevent the incident from occurring.

In this study, it was noted that $88 \%$ of students have never been a cyberbullying victim. It is a positive outcome of this study because cyberbullying causes negative impacts on the victims of cyberbullying. Based on a past study, "sorrow" is a feeling of distress that is more intense than sadness, "disappointment" is a state of displeasure caused by non fulfillment of expectations, "anger" is an uncomfortable response to provocation, "hatred" is an intense dislike to someone and "loneliness" is an unpleasant emotional response to isolation. These were options that the students had to pick on one or more emotional consequences as the worst incidents they have experienced during the exposure to cyberbullying in the past six months (Arafa et al., 2015). Similar results were found and it was noted that there were a large number of students from 123 students who responded that they had never experienced cyberbullying (Bumpas, 2015). In contrast, a total of 3247 (48.2\%) students reported to be a cyberbullying victim at least once throughout the past 6 months. Therefore, the victims are at risk because of the high rates of negative responses to these cyberbullying issues and leads to develop depression if it lasts for a long time. Exposure to cyberbullying poses many psycho-logical and emotional impacts (Arafa et al., 2015).

This study shows that $86 \%$ of female students have never been cyberbullied. The outcome is not parallel with the study (Lawler\& Molluzzo, 2015). who studied about student's perception of cyberbullying at a major metropolitan university. The survey asked if the respondent was a perpetrator of cyberbullying, and a surprising $12 \%$ $(\mathrm{N}=37)$ answered 'Yes'. Female adolescents, as highly educated girls, were more prone to perpetrate cyberbullying. Similar outcome was also identified in the research about the role of online communication in long-term cyberbullying involvement among girls and boys by (Festl \& Quandt, 2016).

In the research by Chao and $\mathrm{Yu}$ (2017) about associations among different internet access time, gender and cyberbullying behaviours in Taiwan's adolescents indicates that in terms of most frequent Internet access time, found that students check the latest status on social media during their rest time at school were the most affected by attitude toward cyberbullying on cyberbullying behaviour. Most of the students are Internet addicted that they use the Internet for social media, which leads to higher coefficient $(\beta=0.28, t=15.75, p<0.01)$ and explanatory ability $\left(\mathrm{R}^{2}=0.078\right)$. The data reveals that when students are addicted to the Internet, the influence on their cyberbullying behaviours are highly significant. In this current study, it shows that $68 \%$ of the students think they are addicted to social media. So, it will increase the possibility to commit cyberbullying behaviour due to a higher percentage of social media addicts.

This study also found that emotions play a significant role in cyberbullying. Table 6 states that $43 \%$ of the students indicate that emotions are the major factor of cyberbullying on social media besides low confidence level at $24 \%$, bad past experience at $17 \%$, stress at $9 \%$ and revenge at $7 \%$. In a research by (Festl \& Quandt, 2016), adolescents who prefer antisocial online contents interact more frequently in online groups and they have a higher risk of becoming cyberbullying victims because most of the time they use the Internet to express themselves, but leads to cyberbullying due to hatred and being annoyed. The study by DiFonzo (2016) participated by 22 males and 61 females of Brock University students ranging from 18 to 25 years of age shows that majority of the participants were typically annoyed by selfies. These deceiving photos also created a sense of jealousy for selected participants, whereby they wanted to look or be them and therefore were annoyed by the selfies. Based on research by Kim et al. (2017), there was a stronger association between cyberbullying victimization and emotional problems for females than males. Specifically, the coefficient of cyberbullying on emotional problems for females was significantly stronger compared to males $(\mathrm{p}<.001)$.

In this research study, Table 7 shows that the highest number of respondents and percentage for the social media application that respondents often see cyberbullying occurs in Facebook at 37\% ( $=37)$, followed by Instagram at $26 \%(\mathrm{~N}=26)$. This is because these applications are popular throughout the country and are used by majority of the people in their daily life. In a similar study carried out by Johnson et al. (2016).In a study con- 
ducted by Rosli (2018) the popularity of Facebook is consistent with the study. Facebook reported that an average of 968 million daily users for June 2015, and in the 2nd quarter of 2015, Facebook reported 1.49 billion monthly active users (Park, 2015). The most mentioned social media platforms are Facebook $(\mathrm{N}=10,45.4 \%)$ and MySpace (N=3, 13.6\%). Four other platforms include in-person messaging was mentioned twice $(9.1 \%)$ and Twitter, Instagram, and chat rooms received one mention (4.6\%) by Garett et al. (2016). Platform like Facebook, Instagram and Twitter are more commonly used for social interaction among teens and youth.

Meanwhile, Table 8 shows that mean comments are the major form of cyberbullying on social media (58\%), followed by spreading rumours (21\%), posting hurtful pictures or videos (13\%), threat to hurt (6\%) and hacking into account (2\%). In a similar study, Abaido (2019) mentions that social media platforms such as Facebook, Instagram, and Twitter should adopt control measures to ensure safe user experience of social media and filter offensive comments or hate speech. It shows that the most prevalent forms are offensive comments $(63.5 \%)$ and hate speech $(40.5 \%)$.

Moreover, Table 9 shows that $45 \%$ of the respondents felt depressed when they were being cyberbullied. This is because cyberbullying commonly will affect mental health and depression is caused by stress. In a similar, Selkie et al. (2015) mention that participants who had experienced cyberbullying and depression have95\% higher prevalence of three times the likelihood of meeting the clinical criteria for depression compared to those with no cyberbullying experience.

In the present study, Table 10 indicates that $42 \%$ of the respondents feel sad when are involved in cyberbullying. The bully feels satisfied and powerful than feeling happy and proud. A similar study by Johnson et al. (2016) indicated that the majority of participants mentioned that cyberbullying was wrong, did not like to see cyberbullying, and were disappointed when they saw others being bullied or bullied themselves.

This research was carried out to identify the ways to create awareness to society about cyberbullying on social media. Based on Table 11, the study found that the way is to enforce cyberbullying laws. Contrary to this result, all the seven participants in the study by Syahida et al.(2018) suggest that the best way to handle cyberbullying is depending on the seriousness of the problem. (If the cyberbullying involves bigger issues, such as outing, masquerading, dissing, slandering and catfishing, the participants believe that action should be taken. Police reports are advisable as many haters or bullies tend to stop bothering after police reports.

\section{Limitations}

Since the respondents are only focused on female university students, therefore, the findings cannot be generalised that all the students of the university are aware of cyberbullying. Moreover, the study population is confined to one university. In addition, this study only collected data through a survey that may not be suffice to address the in-depth knowledge that is required about the topic. Future research could include in-depth interview techniques to study cyber bullying in higher learning education setting as it is necessary due to the limited knowledge.

The most significant limitation is the time of year this study is conducted. The study was conducted during the Conditional Movement Control Order.

\section{Conclusion}

Various studies have been conducted on cyberbullying from different population and scope. This study was conducted on the cyberbullying among university students. This study discussed on the about awareness of cyberbullying among female students. The findings of this study indicated that the respondents do not experience any cyberbullying behavior on social media. This means that students in this university are aware about cyberbullying on social media. Furthermore, majority of the female students know what cyberbullying means even though majority of the female students are addicted to the social media. However, majority of them did not tell or report about cyberbullying to anyone and ask for help. One of the recommendations is to increase awareness of cyberbullying on social media amongst students or the public by prevention and education programs. Programs should design to educate students and the public pertaining to cyberbullying and the long-term effects on victims are extremely important. Bystander intervention programming is also important. Posters and bulletin boards in residential halls, commuters must be designed to educate and also inform students on the available avenue to seek out for assistance if and when they are a victim of cyber bullying. 


\section{References}

1. Abaido, G. M. (2019). Cyberbullying on social media platforms among university students in the United Arab Emirates. International Journal of Adolescence and Youth, 25(1), 407-420. https://doi.org/10.1080/02673843.2019.1669059

2. Arafa, A., Mahmoud, O.E, \& Senosy, S.A. (2015). The Emotional Impacts Of Different Forms Of Cyber Bullying Victimization In Egyptian University Students. Faculty of Nursing, Beni-Suef University

3. Asanan, Z. Z. T., Hussain, I. A. \& Laidey, N. M. (2017). A study on cyberbullying: Its forms, awareness and moral reasoning among youth. International Journal of Information and Communication Sciences, 2(5), 54. https://doi.org/10.11648/j.ijics.20170205.11

4. Balakrishnan, V. (2015). Cyberbullying among young adults in Malaysia: The roles of gender, age and internet frequency. Computers in Human Behavior, 46, 149-157. doi:10.1016/j.chb.2015.01.021

5. Bumpas, S.N (2015). Cyberbullying Prevention: Intervention Effects on Student Involvement. https://scholarworks.bellarmine.edu/tdc/12

6. Chao, C., \& Yu, T. (2017). Associations among different internet access time, gender and cyberbullying behaviors in Taiwan's adolescents. Frontiers in Psychology, 8. doi:10.3389/fpsyg.2017.01104

7. Chukwuere, J., Chukwuere, P.\& Khumalo, N. (2018). Cyber bullying of female students: An exploration of literature study. 15.

8. Cook, S. (2020, July 3). Cyberbullying facts and statistics for 2020. https://www.comparitech.com/internet-providers/cyberbullying-statistics/

9. Difonzo, A. (2016). Cyberbullying, Social Media \& Fitness Selfies: An Evolutionary Perspective. http://dr.library.brocku.ca/handle/10464/10433

10. Festl, R., \& Quandt, T. (2016). The role of online communication in long-term cyberbullying involvement among girls and boys. Journal of Youth and Adolescence, 45(9), 1931-1945. https://doi.org/10.1007/s10964-016-0552-9

11. Garett, R., Lord, L. R., \& Young, S. D. (2016). Associations between social media and cyberbullying: A review of the literature. $m$ Health, 2, 46-46. https://doi.org/10.21037/mhealth.2016.12.01

12. Grigonis, H. K. (2017, July 22). Social Media: Cyberbullying happens more often on Instagram, A new survey suggest. Digital Trends. https://www.digitaltrends.com/social-media/cyberbullyingstatistics-2017-ditch-the-label/

13. Johnson, L.D., Haralson, A., Batts, S., Brown, E., Collins, C., Buren-Travis, A.V., \& Spencer, M. (2016). Cyberbullying on Social Media Among College Students. https://www.counseling.org/docs/defaultsource/vistas/article_03b0bf24f16116603abcacff0000bee 5e7.pdf?sfvrsn=4;Cyberbullying

14. Kim, S., Colwell, S. R., Kata, A., Boyle, M. H., \& Georgiades, K. (2017). Cyberbullying victimization and adolescent mental health: Evidence of differential effects by sex and mental health problem type. Journal of Youth and Adolescence, 47(3), 661-672. https://doi.org/10.1007/s10964017-0678-4

15. Kshetri, N., \& Voas, J. (2019). Thoughts on cyberbullying. Computer, 52(4), 64-68. https://doi.org/10.1109/mc.2019.2898720

16. Lai, C. S., Mohamad, M. M., Lee, M. F., Salleh, K. M., Sulaiman, N. L., Rosli, D. I., \& Chang, W. V. (2017). Prevalence of cyberbullying among students in Malaysian higher learning institutions. Advanced Science Letters, 23(2), 781-784. https://doi.org/10.1166/asl.2017.7492

17. Lawler, J. P., \& Molluzzo, J. C. (2015). A comprehensive survey on student perceptions of cyberbullying at a major metropolitan University. Contemporary Issues in Education Research (CIER), 8(3), 159-170. https://doi.org/10.19030/cier.v8i3.9347

18. Lenhart, A. (2015, April 9). Teens, Social Media \& Technology Overview 2015. https://www.pewresearch.org/internet/2015/04/09/teens-social-media-technology-2015/

19. Lu, N., Wu, G., Zhang, Z., Zheng, Y., Ren, Y., \& Choo, K. R. (2020). Cyberbullying detection in social media text based on character- level convolutional neural network with shortcuts. Concurrency and Computation: Practice and Experience. https://doi.org/10.1002/cpe.5627

20. Muhammad Shawal, A.R., Shafizan, M., \& Tengku Aisha, M.A. (2017). Predicting the Intention to Cyberbully and Cyberbullying Behaviour Among the Undergraduate Students at The International Islamic University Malaysia. International Journal of Education, Psychology and Counseling. 2. 257-270. 
21. Odora, R. J. (2015). The nature and prevalence of cyber bullying behaviors among South African high school learners. INTERNATIONAL JOURNAL OF EDUCATIONAL SCIENCES, 10(03). https://doi.org/10.31901/24566322.2015/10.03.05

22. Park, M. (2015). Facebook Reports Second Quarter 2015 Results. https://investor.fb.com/investornews/press-release-details/2015/Facebook-Reports-Second-Quarter-2015-Results/default.aspx

23. Patchin, J. W., \& Hinduja, S. (2015). Measuring cyberbullying: Implications for research. Aggression and Violent Behavior, 23, 69-74. https://doi.org/10.1016/j.avb.2015.05.013

24. Quintana-Orts, C., \& Rey, L. (2018). Forgiveness and cyberbullying in adolescence: Does willingness to forgive help minimize the risk of becoming a cyberbully? Computers in Human Behavior, 81, 209-214. https://doi.org/10.1016/j.chb.2017.12.021

25. Rosli, J. (2018, October 27). Malaysia Sixth-Worst in Global Cyber-Bullying Ladder, Survey Shows. Kuala Lumpur, Malaysia. https://www.malaymail.com/news/malaysia/2018/10/27/malaysia-sixth-worst-in-global-cyberbullying-ladder/1687181

26. Selkie, E. M., Kota, R., Chan, Y., \& Moreno, M. (2015). Cyberbullying, depression, and problem alcohol use in female college students: A multisite study. Cyberpsychology, Behavior, and Social Networking, 18(2), 79-86. https://doi.org/10.1089/cyber.2014.0371

27. Şentürk, Ş., \& Bayat, S. (2016). Internet usage habits and cyberbullying related opinions of secondary school students. Universal Journal of Educational Research, 4(5), 1103-1110. https://doi.org/10.13189/ujer.2016.040520

28. Syahida, H., Mohd Idzwan, Y. \& Thuan, N. H. \& Suzana, Z. (2018). Social Media Influencer and Cyberbullying: A Lesson Learned from Preliminary Findings.

29. Whittaker, E., \& Kowalski, R. M. (2014). Cyberbullying via social media. Journal of School Violence, 14(1), 11-29. https://doi.org/10.1080/15388220.2014.949377 